\title{
Empréstimos, tradução e uso na prática terminológica
}

\begin{abstract}
Ana Maria Ribeiro de J esus ${ }^{*}$
Abstract: Assuming the dynamics which is inherent to specialized languages, especially to the scientific areas that are closely related to technological advances, we demonstrate how borrowings, especially from English, are extremely productive on neological formations in these areas. Borrowings are thus a reflection of the influence that languages have on each other. We analyzed a corpus of the field of Astronomy, of which terminology, in Portuguese, was exemplary in this regard. Thus, besides the option of keeping the English term, the texts of the corpus also revealed the use of some 'translation ways' by means of paraphrases, definitory phrases, the presentation of a translation after the English term and especially through calque, which proved to be predominant with regard to lexical creation in the field and it is related to the so-called néologie traductive. We can show, as a result, the current Brazilian astronomical community's response to some translations proposed by astronomers in the late 1980s, who suggested the use of Portuguese unities or neologisms created according to Portuguese's structure over foreign terms.
\end{abstract}

Keywords: borrowings; translation ways; neology; specialized languages.

Resumo: Assumindo a dinamicidade inerente às línguas de especialidade, particularmente nas áreas científicas que mais dependem dos avanços tecnológicos, demonstraremos como os empréstimos, sobretudo do inglês, são extremamente produtivos nas formações neológicas dessas áreas. Os empréstimos são, dessa forma, um reflexo da influência que as línguas exercem umas sobre as outras. Analisamos um corpus do domínio da Astronomia, cuja terminologia, em língua portuguesa, mostrou-se exemplar nesse sentido. Assim, além da opção por manter o termo estrangeiro, os textos do corpus de análise revelam também o amplo uso de formas tradutórias por meio de paráfrases explicativas, enunciados definitórios, apresentação de uma tradução após o anglicismo e, em particular, por meio do decalque, que se mostrou predominante no que concerne à criação lexical no domínio, e que está relacionado à chamada neologia tradutiva. Externamos, com isso, a resposta da comunidade astronômica brasileira atual a algumas traduções propostas por astrônomos no final da década de 1980, que sugeriam que se utilizassem unidades pertencentes à língua portuguesa ou neologismos criados de acordo com sua estrutura em detrimento dos termos estrangeiros.

Palavras-chave: empréstimos; formas tradutórias; neologia; línguas de especialidade.

\footnotetext{
* Doutora em Filologia e Língua Portuguesa pela Universidade de São Paulo. Professora dos cursos de Letras e Letras/ Tradutor das Faculdades Metropolitanas Unidas (FMU) de São Paulo. Email: anaself@usp.br.
} 
J ESUS, A. M. R. Empréstimos, tradução e uso na prática terminológica

\section{Introdução}

Os termos de uma área de especialidade, não raro, são alvo de reflexão entre os próprios especialistas do domínio. A necessidade de harmonização, por um lado, e o uso real de termos diferentes para designar um mesmo objeto ou fenômeno, por outro, incitam não apenas o debate entre terminólogos, mas também entre os profissionais da área, geralmente com vistas à melhoria da comunicação no domínio. As questões referentes aos estrangeirismos, igualmente, atraem a atenção dos especialistas e geram, quase que inevitavelmente, propostas de tradução, que se tornarão consagradas com o uso ou, do contrário, permanecerão como idiossincrasias. Abordaremos algumas dessas questões com exemplos da terminologia da Astronomia, domínio de especialidade com 0 qual 0 autor deste artigo trabalhou durante pesquisa de doutorado. Ao fazer um estudo sobre a neologia dos termos da área, deparamo-nos com interessantes recursos de tradução aos quais os astrônomos recorrem para designar as unidades neológicas.

O corpus de análise constituiu-se de obras as quais classificamos em quatro categorias: 1) dois compêndios de Astronomia geral; 2) 16 teses de doutorado e dissertações de mestrado do Instituto de Astronomia, Geofísica e Ciências Atmosféricas (IAG) da Universidade de São Paulo; 3) 16 números da revista Astronomy Brasil, edição brasileira da mais importante revista de divulgação científica internacional de Astronomia; 4) alguns fascículos do Boletim da Sociedade Astronômica Brasileira. As teses e dissertações foram defendidas entre 2006 e 2009 e pertencem a diversas linhas de pesquisa. Recorremos aos fascículos do Boletim da Sociedade Astronômica Brasileira, que datam de 1989, para analisar algumas traduções então propostas.

Resumimos em dois grandes tipos o processo de criação e expansão lexical: a formação no âmbito da própria língua e a adoção e/ ou adaptação a 
J ESUS, A. M. R. Empréstimos, tradução e uso na prática terminológica

partir do conjunto lexical de uma língua estrangeira - os empréstimos ${ }^{1}$. 0 segundo tipo constituiu o fenômeno manifestado em maior número no domínio da Astronomia. Assim, na maioria dos domínios que envolvem tecnologias avançadas, senão em todos eles, a terminologia padronizada internacionalmente compõe-se, reconhecidamente, de termos da língua inglesa. Por questões sobretudo econômicas e políticas, o inglês constitui, na sociedade contemporânea, a ferramenta básica para se ter acesso à tecnologia, à informação e à comunicação internacional. A estruturação de uma economia aberta a um mercado global assim o exigiu, gerando, consequentemente, uma espécie de globalização linguística. Essa notável expansão da língua inglesa é atestada por Fishman. Nas palavras do autor:

Consideremos ou não o inglês uma língua 'assassina', enxerguemos a sua expansão como globalização benigna ou imperialismo linguístico, seu poderoso raio de ação é inegável e, pelo menos por enquanto, muito difícil de ser interrompido (FISHMAN 1998: 26).

O domínio-objeto do presente trabalho não é exceção a esse fenômeno. Registramos a grande infusão de anglicismos na área, principalmente nas teses e dissertações as quais percorremos na busca por neologismos. Dessa forma, mesmo criadas por pesquisadores brasileiros, muitas denominações surgem em inglês por causa da necessidade de divulgação em forma de publicação em periódicos ou da difusão em congressos internacionais.

\section{A face ideológica dos empréstimos}

Cada língua reage de maneira diferente quanto à recepção e ao tratamento de termos estrangeiros. Alguns autores são categóricos na defesa de uma cultura por meio da língua e de sua difusão. OLIVÉRI (2009), ao

\footnotetext{
${ }^{1}$ A título de conceituação, estamos considerando como estrangeirismos qualquer termo proveniente de um idioma estrangeiro e que, quando assimilado pelos falantes da língua receptora, torna-se um empréstimo. Ou seja, o estrangeirismo é a primeira etapa pela qual passa uma palavra oriunda de outra língua (ALVES 1994: 72). Sendo esta unidade lexical bemaceita e de uso frequente, não mais percebida como externa ao sistema, torna-se um empréstimo, e pode, dessa forma, sofrer alterações fonológicas e/ ou ortográficas.
} 
J ESUS, A. M. R. Empréstimos, tradução e uso na prática terminológica

exprimir essa opinião, refere-se à língua inglesa servindo-se de uma metáfora sobre uma carteira de habilitação:

Il faut donc éviter le dérapage vers le «tout anglais ». Les Européens ont certes intérêt à maîtriser l'anglais qui occupe aujourd'hui une place majeure dans le monde, mais la « distinction » viendra demain des autres langues. L'anglais est à l'image du permis de conduire : ne pas le posséder constitue un handicap mais l'avoir ne donne guère d'assurance en terme d'emploi (OLIVERI 2009: 3).

Ao admitir, mas criticar a dominação da língua inglesa no contexto contemporâneo, afirmando ser uma desvantagem não conhecer essa língua (mesmo que conhecê-la não garanta nada), Olivéri menciona o termo handicap, original do inglês hand in cap. Esse interessante uso, intencional ou não, mostra que é difícil, talvez impossível, estabelecer o controle das influências que as línguas exercem umas sobre as outras. E os empréstimos são um reflexo desse fenômeno. Essa questão denota, por um lado, uma intercambialidade social que contrasta, em um mesmo ambiente, diversas línguas, permitindo as transações linguísticas, ou seja, uma comunicação "universal"; por outro lado, uma busca pela conservação da "genuinidade" do conjunto linguístico de uma comunidade. As marcas visuais com as quais se apresentam os termos estrangeiros nos textos - itálico, aspas, negrito - da mesma forma que as marcas metalinguísticas, externadas por enunciados definitórios ou ainda por expressões como "é chamado", "é denominado", "consiste em", também denotam que aquela unidade é percebida como alienígena.

Dessa forma, uso dos empréstimos - e, como demonstraremos, dos decalques - na terminologia de um domínio bi ou multilíngue está atrelado ao real poder de cada língua e, por isso, a língua reflete o poder da sociedade a qual pertence. Trata-se de uma questão ideológica, que invoca um grau de "subordinação" e de "permissão": se uma cultura é subordinada, sua língua torna-se vulnerável, e a cultura dominante terá a permissão de inserir, por meio da língua, suas unidades lexicais; em outras palavras, o poder político, 
J ESUS, A. M. R. Empréstimos, tradução e uso na prática terminológica

social e econômico de uma cultura pode dominar linguisticamente outra cultura. Essa dominação evolui historicamente. A influência da língua inglesa é recente; ainda em meados do século XX, constava-se o domínio do francês e, antes dele, do latim. 0 inglês é, de fato, a língua mais empregada na comunicação e na divulgação científica e tecnológica do mundo contemporâneo e, ao exportar sua tecnologia, a sociedade norte-americana exporta os termos inerentes a ela; desse modo, a língua inglesa influencia a formação das terminologias estrangeiras e o português brasileiro não está isento dessa influência.

Apesar da tendência que os meios de divulgação (internet, revistas, jornais etc.) têm de traduzir os termos estrangeiros, em especial os neológicos, ou mesmo de atribuir a eles uma denominação vernácula por meio de processos metalinguísticos, os anglicismos, também nesses meios, são recorrentes. Uma edição da revista Astronomy Brasil, por exemplo, estampa, como manchete de capa: "O <deslocamento para o vermelho> que mede distâncias cósmicas" (v. 2, n. 13, 2007). O sintagma vernáculo destacado dificilmente ocorreu nos textos mais científicos do corpus, nos quais cedeu lugar, em quase $100 \%$ dos casos, a seu correspondente redshift e, por isso, prendeu-nos a atenção. Entretanto, no texto referente à manchete da capa, havia, em quatro páginas, apenas uma ocorrência de «deslocamento para 0 vermelho , uma ocorrência do sinônimo «desvio para o vermelho >e todas as outras - 37 ocorrências - mencionavam o processo como redshift (idem, p. 3235). Este último trata-se, perceptivelmente, de um termo mais simples, que se constitui de apenas uma unidade lexical e que porta consigo a carga internacional. Todas as ocorrências estavam grafadas, por outro lado, em itálico, uma das marcas que externa a percepção do termo como estrangeirismo.

De fato, notamos que, algumas vezes, os especialistas não se preocupam em traduzir para o português o termo criado em inglês, usando este último mesmo na comunicação entre eles, em textos escritos ou na sala de aula, como é o caso do famoso Big Bang, com poucas ocorrências do 
J ESUS, A. M. R. Empréstimos, tradução e uso na prática terminológica

correspondente vernáculo Grande Explosão, de forma semelhante ao referido redshift. Outras vezes, não se tem uma tradução satisfatória do termo para 0 português e, dessa forma, os especialistas optam por manter o empréstimo, desde que seja aceito pela comunidade, como ocorre, por exemplo, com early type e late type, como lemos em Machado²:

\begin{abstract}
Hubble chamou as galáxias mais à esquerda do diagrama de <early type >e às mais à direita de $\triangleleft$ ate type>. Embora não haja uma relação evolutiva de idade ao longo da sequência, estes nomes ainda são empregados para designar a posição no diagrama. Também são utilizadas as traduções equivocadas <"tipo jovem" > e <"tipo tardio", que contribuem para o caráter confuso desta nomenclatura (MACHADO 2006: 4).
\end{abstract}

Essa ideia de "tradução equivocada" e de que a nomenclatura em português é de "caráter confuso" revela a imprecisão que os especialistas atribuem à conceituação em português, bem como a fiabilidade na significação da denominação estrangeira. Confirmamos, com um especialista da área, que os termos early type e late type, que retomaremos adiante, ainda não têm uma tradução "aceita".

0 que se infere é que a língua inglesa acabou se fixando, notadamente, como a "língua franca" da comunicação científica e tecnológica, e essa linguagem universal, no sentido lato, é um dos reflexos mais visíveis da globalização. Como afirma SOARES (1997), talvez esse processo seja o "mais eficaz que a história conhece no plano da instauração de uma língua transnacional, ultrapassando modelos imperialistas tradicionais ou processos colonialistas convencionais" (SOARES, 1997). Esse tipo de status atribuído à língua é consequência, como já referimos, do domínio social da comunidade que a exporta e atinge, principalmente, as classes sociais mais privilegiadas. Como confirma CRYSTAL, "é o poder econômico de quem sustenta [a língua] que a mantém e alavanca a sua expansão" (CRYsTAL 1996: 7).

\footnotetext{
${ }^{2}$ Utilizaremos, nas citações, os sinais < > para destacar os termos, de forma a não afetar a formatação de origem.
} 


\section{As formas tradutórias}

Além da opção de se referir a um conceito apenas pelo empréstimo, é frequente, nos textos de especialidade, o recurso a formas tradutórias, seguidas ou não do termo estrangeiro. Registramos formas distintas desses casos de contato da língua estrangeira com a língua vernácula: a) por meio de um decalque; b) por meio de uma tradução após o estrangeirismo; c) por meio uma paráfrase explicativa; d) por meio de uma definição. Em todos esses procedimentos revelou-se o fenômeno da conotação autonímica ${ }^{3}$.

Na maioria das vezes, quando traduzidas, as unidades aparecem na forma decalcada, que nada mais é do que uma forma opaca de uma unidade lexical estrangeira, sendo o termo traduzido e adaptado à estrutura morfossintática do português, como nos seguintes contextos:

De fato, Braun e Birch (2008) fizeram uma análise da razão sinal-ruído na base da zona de convecção e concluíram que para se detectar esse fluxo, com a técnica de বhéliossismologia tempo-distância> ४timedinstance helioseismology) $>$, seria necessário mais de uma década de medições (ERASO 2009: 45).

[...] fazer a conexão entre uma classe de eventos astrofísicos conhecidos como «Gamma-Ray Bursts> (GRB), ou Surtos de Raios Gama>, com seus efeitos sobre o meio interestelar (ISM) circundante e sobre um planeta porventura iluminado pela radiação de alta energia (GALANTE 2009: 10).

Esse tipo de fenômeno é notável, especialmente, nas formações sintagmáticas. Desse modo, as formações que em inglês apresentam a estrutura elemento determinante + elemento determinado transformam-se, na maioria dos casos, na estrutura inversa em português, com o elemento determinado ocupando a primeira posição no sintagma, seguido pelo determinante, de acordo com as regras morfossintáticas do idioma. Esse

\footnotetext{
${ }^{3}$ Segundo o conceito de conotação autonímica, o fragmento mencionado é, ao mesmo tempo, um objeto que se mostra e do qual se faz uso (AUTHIER 1981).
} 
J ESUS, A. M. R. Empréstimos, tradução e uso na prática terminológica

fenômeno está relacionado com o que HeRMANS E VANSTEELANDT (1999) chamam de neologia tradutiva:

\begin{abstract}
Uma primeira observação é a predominância de sintagmas, em nosso corpus de neologismos de tradução, seja qual for a língua do termo fonte. Temos por hipótese que este grande número está ligado ao próprio processo de neologia tradutiva. De fato, se compararmos os neologismos não tradutivos com o resto do corpus, constatamos que a percentagem de sintagmas é maior na segunda categoria ${ }^{4}$ (HERMANS; VANSTEELANDT 1999: 39).
\end{abstract}

Os decalques não são necessariamente seguidos do termo de origem ou antecedidos por ele. Nesse caso, pode-se ignorar o caráter estrangeiro do termo, tornando-se o decalque, como afirmamos, uma espécie de empréstimo camuflado. Para identificar esse caráter na unidade lexical, é necessário que se realize uma pesquisa em textos em outras línguas. Elencamos outros exemplos de decalque nos contextos a seguir, os quais fazem referência ao termo de partida:

Este fenômeno - conhecido como «escurecimento gravitacional> $\varangle$ gravity darkening) > - é mais evidente em estrelas com alta rotação (...) (TEODORO 2009: 17).

Burton formulou a hipótese de que tais distorções resultam dos chamados $\varangle$ movimentos de corrente $>\triangleleft$ streaming motions) $>$ associados aos braços espirais (J UNQUEIRA 2009: 38).

J untos resultaram em numerosas amostras de estrelas MP da Galáxia e posterior identificação de <estrelas pobres em metais enriquecidas em carbono $>(<C E M P>$, «carbon-enhanced metal-poor $>$ (ALMEIDA 2009: 27).

Observamos, no primeiro contexto anterior, que houve apenas a inversão de modo que o sintagma fosse adaptado à estrutura da língua portuguesa. No segundo caso, a adaptação à estrutura da língua portuguesa

\footnotetext{
${ }^{4}$ Une première observation est la prédominance de syntagmes, dans notre corpus de néologismes de traduction et ce, quelle que soit la langue du terme-source. Nous émettons l'hypothèse que ce grand nombre est lié au processus même de la néologie traductive. En effet, si l'on compare les néologismes non traductifs avec le reste du corpus, on constate que le pourcentage de syntagmes est plus élevé dans la seconde catégorie.
} 
J ESUS, A. M. R. Empréstimos, tradução e uso na prática terminológica

exigiu que o determinante fosse seguido pelo sintagma preposicionado e, no último exemplo, o decalque resulta em uma composição sintagmática bastante complexa, com dois adjetivos seguidos, cada um, de um sintagma preposicionado.

Registramos, também, a manifestação do enunciado tradutório sob a forma de um correspondente em português. Nota-se, no contexto a seguir, que, mesmo após inserir a tradução de waiting point entre parênteses, 0 autor utilizou o anglicismo, e não a tradução, para se referir ao sintagma pela segunda vez:

Quando a captura de nêutrons é interrompida, temos o chamado $<$ Waiting Point $><$ ponto de espera) $>$, que é 0 ponto onde 0 decaimento $B$ deve ocorrer antes que mais nêutrons sejam adicionados. Para cada $Z$ existe um <waiting point $>$ distinto, que por sua vez também depende de T e Nn (PLACCO 2007: 16).

De modo semelhante a uma tradução do termo, o autor do texto pode servir-se do recurso das paráfrases para explicar um termo estrangeiro. Esse recurso é isolado no contexto por meio de travessões ou entre parênteses, como vemos na paráfrase explicativa do termo eraly-AGB, destacada no seguinte contexto:

\footnotetext{
A AGB pode ser dividida em duas fases: (i) a <early-AGB $>\triangleleft$ estrelas que acabaram de entrar na fase $A G B)>$, onde a camada que queima $\mathrm{H}$ se extinguiu devido a expansão do envoltório e a luminosidade é provida da camada que queima He (...) (J UNQUEIRA 2009: 42).
}

Outro recurso que visa a descrição de uma unidade neológica estrangeira é um enunciado em forma de definição, que pode ser empregado após o estrangeirismo. Esse recurso, bem como os dois anteriores, parece indicar que o emissor é consciente de que o estrangeirismo pode não ser compreendido por seu interlocutor. Desse modo, dispõe-se de uma definição da unidade lexical, no intuito de esclarecer o conceito descrito: 


\begin{abstract}
Usando nossos modelos magneto-hidrodinâmicos, auto-consistentes, tri-dimensionais (sic), estimamos para ventos de estrelas da pré Sequência Principal a escala temporal de migração planetária devido a forças de arraste exercidas pelo vento em um planeta tipo «hotJupiter $>$ ४i.e., um planeta gigante que orbita muito próximo da estrela)> (VIDOTTO 2009: xii).
\end{abstract}

Além da reformulação frásica definicional, é notável o uso da forma inglesa de Júpiter quente (hot-J upiter) nesse exemplo, extraído de uma tese, no ano de 2009. Na revista de divulgação científica Astronomy Brasil, em 2006, o termo já havia sido grafado em português, em reportagem que comentava sobre a descoberta de planetas extrassolares:

Até agora esses < $<$ úpiters quentes" $>$ têm sido considerados mundos exóticos da caça ao tesouro de exoplanetas ( $A B$, n. 9, p. 31).

É por isso que os teóricos passaram a investir mais na ideia de migração de planetas quando foram descobertos os primeiros ४júpiters quentes $>(A B$, n. 9, p. 35).

Tal fato permite-nos descrever dois fenômenos: a instabilidade denominativa, em que o conceito, geralmente neológico, é denominado alternativamente por duas ou mais formas diferentes, o que conduz à variação denominativa, nesse caso estrangeira e vernácula; e, mais uma vez, a opção pelo uso de anglicismos no meio científico e pela língua vernácula nos meios de divulgação.

\title{
4. Dos anos 1980 aos dias atuais. Propostas de tradução e uso efetivo
}

Em 1989, alguns membros da Sociedade Astronômica Brasileira (SAB) iniciaram, em um boletim periódico, uma nova sessão denominada Nomenclatura, que tinha como objetivo "propiciar a discussão sobre 
J ESUS, A. M. R. Empréstimos, tradução e uso na prática terminológica

traduções para o português de termos astronômicos difíceis ou controversos, para que se chegue a formas aceitáveis pela comunidade astronômica" (TORRES; MACIEL 1989: 22). Os autores pretendiam, assim, privilegiar os termos de uso consagrado pela comunidade e sugeriam que se utilizassem unidades pertencentes à língua portuguesa ou neologismos criados de acordo com sua estrutura. Reconhecendo-se como os principais usuários da nomenclatura, pretendiam "propor uma terminologia correta, que se constituirá em uma contribuição ao acervo da língua portuguesa" (idem). Portanto, assim como a União Astronômica Internacional, a SAB tem a autoridade, no Brasil, de sugerir e harmonizar a terminologia da área.

Torres e Maciel comentam, por exemplo, a respeito dos sintagmas early type star/late type star, que, como mostramos anteriormente, ainda hoje são considerados problemáticos. A proposta dos autores para uma tradução "adequada à semântica do termo em português" é que se considere a ordem dessas estrelas na sequência espectral. Eles elencam, então, algumas traduções alternativas para early e late, como avançado/tardio, e outras consideradas "inexatas", como prematuro/pós-maturo; e sugerem, finalmente, os sintagmas vernáculos <estrelas dos tipos iniciais> ou «dos primeiros tipos»; <estrelas dos tipos finais> ou <dos últimos tipos> (TORRES; MACIEL 1989: 23).

Continuando a discussão em outro número do boletim, Torres e Maciel apresentam uma lista de sugestões de tradução. Eles denominam "barbarismos desnecessários" algumas traduções que surgem na área porque contam com uma palavra que tem acepção diferente em português, alterando o sentido do termo. Quanto à criação de neologismos, abordam os autores:

Até recentemente era usual em ciência a utilização de termos latinos ou gregos. Com o predomínio do informalismo americano, palavras mais comuns ou mesmo gírias passaram a ser adotadas. Quando não pudermos nos valer de outras línguas neolatinas, ou de analogia com outras ciências, ou ainda o radical grego parecer muito rebuscado, parece preferível exercitar um pouco a imaginação, ao invés de usar barbarismos [... ] (TORRES; MACIEL 1989: 15). 
J ESUS, A. M. R. Empréstimos, tradução e uso na prática terminológica

A partir dessas afirmações categóricas, analisamos, então, alguns dos termos listados nos fascículos, para se ter uma ideia do que ocorreu desde sua publicação até os dias atuais, por meio da comparação com os dados do corpus levantado em nossa pesquisa. Observemos as seguintes sugestões de tradução, transcritas exatamente como no boletim (termo em inglês tradução sugerida):

- Accretion disk - disco de acresção, ou de acréscimo.

- Mass accretion - acresção ou acréscimo de massa.

- Massive star - estrela massiva (notar que o termo "maciça" não tem o mesmo significado).

- Horizontal branch - ramo horizontal.

Constatamos, no corpus atual, que se aderiu à sugestão de tradução dos termos citados anteriormente, tanto nos livros acadêmicos quanto nas teses e dissertações. Para accretion, o termo optado pela comunidade astronômica foi acresção em vez de acréscimo. A unidade lexical maciça realmente não teve ocorrências, sendo utilizada a tradução sugerida massiva.

A maioria das propostas de tradução, entretanto, não foi acatada. Em alguns casos se fez uso de outra forma tradutória e, em outros, manteve-se 0 empréstimo, como ocorre, por exemplo, com a unidade lexical envelope (que forma o termo envelope convectivo, por exemplo), que é decalcada da forma homônima do inglês, e é criticada por Torres e Maciel, que sugerem outra tradução para o termo: "de preferência 'invólucro', ou 'envoltória'. 0 termo 'envelope' é menos correto, embora seja utilizado em inglês e francês" (TORRES; MACIEL 1989: 15). Não localizamos no corpus analisado, entretanto, qualquer ocorrência dos dois termos propostos, nem mesmo na obra Astronomia: uma visão geral do Universo (Friaça et al. 2006), do mesmo instituto dos dois autores. 0 termo em uso, em língua portuguesa, continua sendo envelope. Do mesmo modo, as sugestões seguintes são algumas das que 
se comportaram, no corpus atual, de forma diferente da proposta (termo em inglês - tradução sugerida):

- Novalike - novóide.

O termo "novóide" não foi encontrado em nenhuma fonte. Em algumas teses, entretanto, registrou-se o empréstimo (com variação ortográfica), tanto no singular quanto pluralizado: "É classificada como uma «nova-like> do tipo UX UMa e é um sistema não eclipsante" (RIBEIRO 2006: 166).

Foram observadas linhas ressonantes no ultravioleta [...] com componentes em absorção desviadas para o azul em novas anãs, remanescentes de novas clássicas e «nova-likes> com alta taxa de acresção (RIBEIRO 2006: 31).

- ZAMS - SPIZ (!) parece cômico, mas está correto: sequência principal de idade zero.

Não encontramos o acrônimo SPIZ no corpus, mas seu correspondente em inglês, novamente, foi localizado: "A linha tracejada quase horizontal representa o limite máximo de massa da secundária na <ZAMS> preenchendo lobo de Roche" (RIBEIRO 2006: 173). Podemos fazer uma analogia entre esses acrônimos e os termos da Medicina "AIDS", em inglês, e "SIDA", acrônimo da tradução em língua portuguesa "Síndrome da Imunodeficiência Adquirida". Ambos estão registrados na literatura médica e têm recorrência até na mídia, em textos jornalísticos. 0 acrônimo em inglês, entretanto, está muito mais cristalizado, de tal forma que "SIDA", mesmo estando em língua vernácula, causa estranhamento. Daí o ponto de exclamação que utilizaram Torres e Maciel após "SPIZ", denotando o estranhamento causado pelo acrônimo da tradução.

- Edge-on - vista de perfil. Exemplo: Edge-on galaxy - galáxia vista de perfil. 
J ESUS, A. M. R. Empréstimos, tradução e uso na prática terminológica

O sintagma "vista de perfil", da mesma forma, não foi localizado no nosso conjunto de textos. Porém, neste caso, encontramos traduções, mas diferentes da proposta, e sempre retomando entre parênteses o termo em inglês, como nos dois contextos a seguir: " $[\ldots]$ se $\mathrm{i}_{\mathrm{He}}=0$ 0, o disco equatorial é visto de frente (face-on) e se $\mathrm{i}_{\mathrm{He}}=90$ o, ele é <visto de lado> 4 edge-on)>" (TEODORO 2009). "[...] o sistema «visto de borda> ४(edge-on)> possui uma inclinação orbital de 90 graus" (RIBEIRO 2006).

- Hertzprung gap - lacuna de Hertzprung, ou falha de Hertzprung. Esta última forma é usada em "falha de Kirkwood" (Kirkwood gap).

Sem qualquer ocorrência de falha ou lacuna, foi encontrada a formação híbrida com o uso do correspondente em inglês gap: "Estamos tratando de um sistema com período acima de um <gap de períodos> e uma massa da secundária típica de sistemas abaixo do 〈gap de períodos》, embora não se note a existência de «gap de períodos> para novas clássicas" (RIBelRo 2006: 163).

Dentre outras ocorrências, registramos, por fim, uma sugestão, com caráter de advertência, de nível fonológico. De acordo com Torres e Maciel, o termo "ápex", como em "ápex solar" e "ápex do Sol" - traduções propostas para o termo Solar apex - deve ser pronunciado com a tônica na primeira sílaba, e não como oxítona ("apéx"), como estariam fazendo os membros da comunidade.

Entretanto, a tentativa de manipulação de uma linguagem por meio da imposição de usos fica, muitas vezes, sem resposta. A harmonização é extremamente necessária, em especial no âmbito de uma ciência tão séria, e parece ser muito bem conduzida pelos organismos responsáveis no domínio da Astronomia. A comunidade linguística, entretanto, é viva, evolui, e não está isolada, mas inserida em um contexto sócio-histórico, cultural e ideológico 
que, inevitavelmente, perpassa a língua, e faz transparecer, através dela, sua influência e sua mudança.

\section{Considerações finais}

Tentativas de harmonização são e sempre serão bem-vindas, manuais são necessários, glossários, listas de prioridades, bem como diretrizes para a criação lexical. Nisso consiste a organização da ciência, como em uma ontologia, no sentido filosófico. Ao mesmo tempo, a aceitação dos estrangeirismos - ou melhor, do inglês - adentrando os termos vernáculos é, paradoxalmente, uma forma de harmonização, pelo caráter de língua internacional, ao lado do anseio de inserção do país dentre os mais respeitados no domínio de pesquisa; e, por outro lado, a aceitação da variação, dos termos da língua geral na nomenclatura da área, das diferenças históricas, das metáforas, é sinal da humanidade da língua, ainda que nos domínios mais especializados.

Assim, a influência de empréstimos da língua inglesa nas formações neológicas manifesta-se, nos textos de especialidade, de várias formas. Além do estrangeirismo, ou seja, da transposição de todo o significante, o decalque, o qual consideramos uma forma não transparente do empréstimo, se fez presente em grande parte dos contextos, em especial no corpus de divulgação científica. Esse fato denota que, ao influenciar o estilo da escolha lexical por meio do recurso ao decalque, o inglês reitera-se como língua de prestígio na comunicação especializada.

Outros processos são recorrentes, ocorrendo antes ou depois do termo estrangeiro: a tradução para o português, o uso de uma paráfrase explicativa, o recurso a um enunciado definitório. Esses recursos, bem como as marcas visuais, causam, de certa forma, um distanciamento da língua receptora e parecem indicar que o emissor é consciente de que o estrangeirismo pode não ser compreendido por seu interlocutor. 
J ESUS, A. M. R. Empréstimos, tradução e uso na prática terminológica

Além dessas formas tradutórias, registramos outros recursos 5 , como formações híbridas, ou seja, sintagmas formados por elementos em língua vernácula e em inglês, bem como formações híbridas com termos e siglas. Observamos, ainda, certa preocupação por parte dos autores em retomar 0 termo em língua inglesa após o termo vernáculo, dando a perceber a necessidade do autor de se fazer compreender e de confirmar a exatidão deste último.

Dessa forma, por um lado, mostra-se o reflexo das diversidades culturais, demarcado por reações quase puristas aos termos estrangeiros ou por meio da opção por criações próprias da língua vernácula e inerentes à cultura de chegada. Por outro lado, o reflexo de um mundo globalizado, em que a comunicação e a informação se alastram rapidamente, é obtido por meio da denominação dos termos a partir de empréstimos ou de uma espécie de "tradução literal", em que os termos são apenas adaptados à estrutura da língua receptora. Esse aspecto externa, igualmente, o caráter da internacionalização da nomenclatura científica e, dessa forma, a língua cumpre seu papel da comunicação.

Não nos parece necessário impedir, pelo menos na atual conjuntura histórica e cultural, a disseminação dos termos ingleses na área da Astronomia. Se não há comunicação, não há difusão de conhecimento e, uma vez que a tecnologia e os avanços científicos são exportados principalmente por meio da linguagem, tal fato impediria a entrada, no País, de tudo que se refere à evolução da área (instrumentação astronômica, programas computacionais etc.). Com a aceitação de uma linguagem global e comunicativa, torna-se mais conveniente dispor o Brasil em pé de igualdade com os países desenvolvidos e mais influentes na pesquisa astronômica e, ao mesmo tempo, exportar os conhecimentos aqui surgidos.

\footnotetext{
${ }^{5}$ Apesar desses recursos não terem sido exemplificados no presente artigo, comentamos sua ocorrência pela pertinência do tema.
} 


\section{Referências bibliográficas}

AlmeIDA, T. M. A origem do carbono no Universo: insights a partir de observações de estrelas pobres em metais nas nuvens de Magalhães. Dissertação (Mestrado em Astronomia) - Instituto de Astronomia, Geofísica e Ciências Atmosféricas, Universidade de São Paulo, São Paulo, 2009.

ALVES, I. M. Neologismo: criação lexical. 2.ed. São Paulo: Ática, 1994.

ASTRONOMY BRASIL: Revista de divulgação internacional de Astronomia. São Paulo: Duetto Editorial; Andromeda. Vários volumes, 2006-2007.

CRYSTAL, D. English: the global language. Washington: US English, 1996.

ERASo, G. A. G. Estudos numéricos do dínamo Solar. Tese (Doutorado em Astronomia) - Instituto de Astronomia, Geofísica e Ciências Atmosféricas, Universidade de São Paulo, São Paulo, 2009.

FISHMAN, J. The new linguistic order. Foreign Policy, n. 113, p. 26-40, 1998.

FrIAÇA, A. et al. Astronomia: uma visão geral do Universo. São Paulo: Edusp, 2006.

Galante, D. Efeitos astrofísicos e astrobiológicos de Gamma-Ray Bursts. Tese (Doutorado em Astronomia) - Instituto de Astronomia, Geofísica e Ciências Atmosféricas, Universidade de São Paulo, São Paulo, 2009.

Hermans, A.; VAnsteelandT, A. Néologie traductive. Terminologies nouvelles, $\mathrm{n}$. 20, p. 37-43, 1999. Disponível em: বhttp:// www2.cfwb. be/ franca/termin/ charger/ rint20.pdf>. (02/ 04/2009).

J ESUS, A. M. R. Terminologia da Astronomia: estudo da neologia e da variação. Tese (Doutorado em Filologia e Língua Portuguesa) - Faculdade de Filosofia, Letras e Ciências Humanas, Universidade de São Paulo, São Paulo, 2011.

J UNQUEIRA, T. C. Determinação da curva de rotação galáctica e estudo do mínimo próximo a $R_{0}$. Dissertação (Mestrado em Astronomia) Instituto de Astronomia, Geofísica e Ciências Atmosféricas, Universidade de São Paulo, São Paulo, 2009.

MACHADO, R. E. G. Halos triaxiais e a razão axial de galáxias espirais. Dissertação (Mestrado em Astronomia) - Instituto de Astronomia, Geofísica e Ciências Atmosféricas, Universidade de São Paulo, São Paulo, 2006.

OLIVERI, C. Plurilinguisme et identité culturelle européenne. Les Cahiers de I'ASDIFLE, n. 4, 2009. Disponível em: «ttp:// fle. asso. free. fr/ asdifle/ Cahiers/ Asdifle_Cahier\%204_Olivieri.pdf $>$. (18/05/2010). 
PLACCO, V. M.Padrões de abundâncias entre estrelas muito pobres em metais no halo da galáxia. Dissertação (Mestrado em Astronomia) - Instituto de Astronomia, Geofísica e Ciências Atmosféricas, Universidade de São Paulo, São Paulo, 2007.

RibeiRo, F. M. A. Uma análise espectroscópica de discos de acresção em variáveis cataclísmicas. Tese (Doutorado em Astronomia) - Instituto de Astronomia, Geofísica e Ciências Atmosféricas, Universidade de São Paulo, São Paulo, 2006.

SOARES, D. A Globalização numa perspectiva sociocibernética. Contracampo, Rio de J aneiro, n. 1. UFF, jul/ dez 1997.

TeOdoRo, M. M. Análise multi-espectral dos eventos cíclicos de $n$ Carinae. Tese (Doutorado em Astronomia) - Instituto de Astronomia, Geofísica e Ciências Atmosféricas, Universidade de São Paulo, São Paulo, 2009.

TorRes, C. A. P. C. O; MACIEL, W. J. Nomenclatura. Boletim da Sociedade Astronômica Brasileira, São Paulo, 1989, v. 11, p. 15-23.

VIDOTTO, A. A. Three-dimensional numerical simulations of magnetized winds of low-mass stars. Tese (Doutorado em Astronomia) - Instituto de Astronomia, Geofísica e Ciências Atmosféricas, Universidade de São Paulo, São Paulo, 2009. 